\title{
A construção de uma historiografia autoritária pelo Estado Novo de Getúlio Vargas: o caso da revista Cultura Política $(1941-1945)^{*}$
}

The construction of an authoritative history of the New State of Getúlio Vargas: the case of the magazine Culture Policy (1941-1945)

\section{Rafael Nascimento Gomes}

Doutorando do Programa de Pós-Graduação em História da Universidade de Brasília rafaelnascimentogomes@gmail.com

Resumo: Esse artigo propõe-se a analisar as visões de história do Brasil disseminadas durante a Ditadura do Estado Novo de Getúlio Vargas (1937-1945). Em outras palavras, busca-se apresentar os esforços governamentais voltados para uma releitura da história brasileira. Para isso utiliza-se como principal fonte a revista Cultura Política, editada pelo Departamento de Imprensa e Propaganda (DIP), vinculado diretamente à Presidência da República, entre 1941 e 1945.

Palavras-chave: História Política, Historiografia brasileira, Getúlio Vargas.

\begin{abstract}
This article proposes to examine the views of the history of Brazil disseminated during the dictatorship of the New State of Getúlio Vargas (1937-1945). In other words, it seeks to present the government efforts toward a reinterpretation of Brazilian history. For this is used as the main source the magazine Culture Policy, published by the Department of Press and Propaganda (DIP), linked directly to the presidency, between 1941 and 1945.

Keywords: Political History, Brazilian historiography, Getulio Vargas.
\end{abstract}


Estas páginas refletem esse espetáculo extraordinário de renascimento do Brasil Novo. Elas constituem um depoimento vivo e irretorquível do espírito de paz, de concórdia, de tolerância e de unidade que hoje desfrutamos. Cultura Política, set. 1941.

\section{Introdução}

Uma versão da história do Brasil tornou-se objeto de políticas públicas na área da cultura. A proposta de história nacional construída durante a Ditadura do Estado Novo (1937-1945) marcou a cultura histórica do nosso país durante muito tempo, sendo seus ecos sentidos até hoje. Dessa forma, o texto que se segue procura delinear as interpretações de história do Brasil que foram elaboradas e divulgadas pelo próprio Estado Novo de Getúlio Vargas, detendo-se tanto nos agentes e instrumentos mobilizados, quanto na observação dos conteúdos propostos como informações e valores de uma cultura histórica nacional. Foram privilegiados, dessa forma, os pontos fortes e de convergência detectados ao longo da análise, mas, como seria de esperar, existe, na construção do estado-novista, uma série de fissuras, tensões e oposições.

Para isso, utiliza-se a revista Cultura Política, publicada pelo Departamento de Imprensa e Propaganda (DIP) entre 1941 e 1945. A circulação desse periódico responsabilizou-se pela montagem de um passado comum ao Estado nacional, passado este que devia ser o produto de uma tradição e precisava ser o objeto de uma política de divulgação de largo espectro.

\section{Intelectuais e Estado: uma aliança necessária para a construção de um projeto "nacional"}

A relação dos intelectuais com o sistema de poder tem sido extremamente imbricada e complexa, uma vez que, ao longo da história, eles frequentemente atribuíram a função de agentes da consciência e do discurso. No Brasil, como lembra Mônica Pimenta Velloso, a nossa estrutura patriarcal e autoritária e a própria condição de país periférico acabaram por reforçar ao extremo este tipo de prática. Assim, o ideal de representação, o falar em nome dos destituídos de capacidade de discernimento e expressão, foi facilmente absorvido pelo intelectual brasileiro. Sentindo-se consciência 
privilegiada do "nacional", ele constantemente reivindicou para si o papel de guia, condutor e arauto (VELLOSO, 1987: 1-2).

Marcelo Barbosa Câmara destaca que do ponto de vista da pesquisa acadêmica, há uma vasta literatura sobre o tema Estado Novo, entretanto a pesquisa acerca do pensamento político que circundava o regime de 1937 e que ele próprio buscou em muitos de seus princípios assumir enquanto ideário do regime, esta sim continua não suficientemente explorada e se explorada não foi tida como um conjunto de análises relevantes no tocante a um pensamento político que refletiu de forma apropriada a cultura política do Brasil. Há pesquisas acerca do tema cultura política e sobre pensamento político autoritário e a revista Cultura Política, porém, não se leva em consideração a produção intelectual dos autores ditos autoritários ou em específico da revista dirigida por Almir de Andrade como fonte de estudo sobre cultura política (CÂMARA, 2010: 50-54).

Mônica Pimenta Velloso defende que é a partir da década de 1930 que os intelectuais passam sistematicamente a direcionar a sua atuação para o âmbito do Estado, tendendo a identificá-lo como a representação superior da ideia de nação. Percebendo a sociedade civil como corpo conflituoso, indefeso e fragmentado, os intelectuais corporificam no Estado a ideia de ordem, organização, unidade. Assim, ele é o "cérebro" capaz de coordenar e fazer funcionar harmonicamente todo o organismo social. Apesar das diferentes propostas de organização apresentadas pelos intelectuais ao longo das décadas de 1920 e 1930- jurídica (Francisco Campos), econômica (Azevedo Amaral), espiritual (Jackson de Figueiredo)-, todas convergem para um mesmo ponto: a solução autoritária e a desmobilização social (CÂMARA, 2010: 3).

E é durante a ditadura do Estado Novo de Getúlio $\operatorname{Vargas}^{1}$ (1937-1945) que esta matriz autoritária de pensamento, que confere ao Estado o poder máximo da organização social, vai adquirir contornos mais definidos. As elites intelectuais, das mais diversas correntes de pensamento, passam a identificar o Estado como cerne da

\footnotetext{
${ }^{1}$ Vargas foi o presidente brasileiro que mais tempo permaneceu no poder (1930-1945; 1950-1954), e por múltiplas faces: "revolucionário", presidente constitucional, ditador, e até mesmo, democrático. Natural de São Borja (RS), cidade fronteiriça com a Argentina, Getúlio Dornelles Vargas ingressou na vida pública em 1909, como deputado estadual pelo PRR (Partido Republicano Rio-Grandense). De 1922 a 1926, cumpriu o mandato de deputado federal. Foi também ministro da Fazenda do governo Washington Luís; deixou o cargo em 1928, quando foi eleito governador de seu estado. Foi o principal líder da chamada "Revolução de 1930", que derrubou o então presidente Washington Luís. Em novembro de 1937, instaurou a ditadura do Estado Novo que durou até outubro de 1945, quando foi deposto pelo Alto Comando do Exército.
} 
nacionalidade brasileira. E a produção historiográfica, ainda que não feita por historiadores profissionais, mostrou-se importante nesse processo.

Dentro do projeto político-pedagógico do Estado Novo há que se distinguir dois níveis de atuação e estratégia: a do Ministério da Educação, sob o comando de Gustavo Capanema, e a do Departamento de Imprensa e Propaganda (DIP), sob a égide de Lourival Fontes. Entre essas entidades ocorreu uma espécie de divisão do trabalho, visando atingir distintas clientelas: o ministério Capanema voltava-se para a formação de uma cultura erudita, preocupando-se com a educação formal; enquanto o DIP buscava, através do controle das comunicações, orientar as manifestações da cultura popular (VELLOSO, 1987: 4-5).

Capanema reunia um grupo de intelectuais ligado à vanguarda do movimento modernista: Carlos Drummond de Andrade (chefe de gabinete), Lúcio Costa, Oscar Niemeyer, Cândido Portinari, Mário de Andrade. Bem diferente era a composição em torno de Lourival Fontes, que incluía nomes como o de Cassiano Ricardo, Menotti del Picchia e Cândido Motta Filho. Intelectuais estes conhecidos pelo pensamento centralista e autoritário, que viria a imprimir um rígido controle nos meios de comunicação. É este grupo que vai dar as linhas mestras da política cultural direcionada às camadas populares.

No Estado Novo, portanto, o intelectual responde à chamada do regime que o incumbe de uma missão: a de ser o representante da consciência nacional. O trabalho do intelectual - agora engajado nos domínios do Estado - deve traduzir as mudanças ocorridas no plano político. O melhor exemplo que temos para ilustrar esta nova concepção de intelectual é a entrada de Getúlio Vargas para a Academia Brasileira de Letras, em dezembro de 1943. Esse evento veio para reforçar um dos postulados doutrinários mais enfatizados pelos representantes do regime: o da união entre o homem de pensamento e o homem de ação, entre a política e a literatura, enfim, entre os intelectuais e o Estado. Vargas personifica magistralmente esta simbiose, reunindo em si os atributos do verbo e da ação, de idealismo e pragmatismo. É apresentado como o político competente, capaz de comandar o jogo político, mas também é o intelectual capaz de refletir sobre os destinos da nacionalidade, na qualidade de autor da "nova política do Brasil” (VELLOSO, 1987: 12).

A doutrina do regime procurou realizar um corte histórico no tempo, mostrando que o presente veio expurgar os erros do passado. As expressões como "Estado Novo", "Brasil Novo", "nova ordem", entre várias outras, denotam esta tentativa de marcar o 
regime como uma fase de redenção, de "encontro do Brasil consigo mesmo". Esta redenção só pode adquirir sentido, quando contraposta a um período de caos, desordem e desajuste. O liberalismo aparece, então, como a corporificação deste mal, como um verdadeiro desastre para a nacionalidade brasileira, porque seria uma ideologia importada. É, portanto, a partir da prática liberal que os doutrinadores do regime explicam todos os males que se abateram sobre o país.

É precisamente esta retórica antiliberal que fundamentou o novo papel atribuído ao intelectual. Assim, no liberalismo era aceitável que o intelectual fosse inimigo do Estado, porque este não representava o verdadeiro Brasil. No Estado Novo tal fato não ocorreria mais: o Estado se transformava no tutor, no pai da intelectualidade, ao se identificar com as forças sociais. De inimigo do Estado, o intelectual deve se converter em seu fiel colaborador, ou seja, ele passa a ter um dever para com a sua pátria.

\section{O DIP como instrumento político-cultural}

Com isso, observa-se que durante o Estado Novo elaborou-se, efetivamente, a montagem de uma propaganda sistemática do governo, destinada a difundir e popularizar a ideologia do regime junto às diferentes camadas sociais. Para dar conta de tal empreendimento, é criado um eficiente aparato cultural: o Departamento de Imprensa e Propaganda (DIP), diretamente subordinado ao Executivo.

Criado pelo decreto presidencial de dezembro de 1939, o Departamento de Imprensa e Propaganda, sob a direção de Lourival Fontes, viria a materializar toda a prática propagandista do governo. Seu objetivo, como apresenta Ângela de Castro Gomes, tinha como duas faces opostas e complementares. Tratava-se de difundir amplamente a imagem do novo regime que se instalara em novembro de 1937 e de combater a veiculação de todas as mensagens que lhe fossem contrárias. Para tanto, o órgão deveria ser um grande mecanismo de promoção da figura do chefe de Estado, das autoridades que o cercavam e das iniciativas políticas então implementadas, produzindo e divulgando o noticiário oficial e supervisionando todos os instrumentos de comunicação de massa. O alcance dessa proposta, lembra a historiadora, traduzia-se na estrutura do próprio órgão, dividido em cinco seções: propaganda, radiodifusão, cinema e teatro, turismo e imprensa (GOMES, 1996: 126).

Assim, essa estrutura altamente centralizada iria permitir ao governo exercer eficiente controle de informação, assegurando-lhe considerável domínio em relação à 
vida cultural do país. A centralização administrativa era apresentada como fator de modernidade, apelando-se para os princípios de sua eficácia e racionalidade. Em outras palavras, o DIP funcionava como organismo onipresente que penetrava todos os poros da sociedade. Este órgão do Estado construiu uma ideologia que abarcou desde as cartilhas infantis aos jornais nacionais, passando pelo teatro, música, cinema e marcando a sua presença inclusive no carnaval.

Através das publicações oficiais do regime, como a revista Cultura Política (direção de Almir de Andrade) e o jornal A Manhã (direção de Cassiano Ricardo) é possível ter-se uma dimensão da eficiência do Estado na montagem do seu projeto cultural e, portanto, de sua visão de História desejada a ser lançada e disseminada para a sociedade. As publicações surpreendem pela sua capacidade organizativa em termos editoriais e intelectuais. Reunindo as correntes mais heterogêneas da intelectualidade brasileira como o escritor Carlos Drummond de Andrade, o jurista Oliveira Viana, a poetisa Cecília Meireles, o sociólogo Gilberto Freyre, o poeta Vinícius de Moraes, o advogado integralista Gustavo Barroso, os escritores José Lins do Rego, Manuel Bandeira e outros; o jornal procurou atrair para o seio do Estado toda a elite intelectual do período, integrando-a ao regime. O mesmo ocorreu com a revista Cultura Política que contou entre os seus colaboradores com o militar e historiador Nelson Werneck Sodré, Gilberto Freyre e até com o escritor opositor de Vargas, Graciliano Ramos.

A questão do nacionalismo, acirrada na conjuntura de guerra, funcionava como um poderoso elemento aglutinador, capaz de integrar quase toda a intelectualidade do período. A revista é enfática nesse sentido, quando afirma aceitar a colaboração de todos, independente de seu cunho ideológico. Declara não ter partidos políticos, pois a sua preocupação fundamental é a de "espelhar tudo o que é genuinamente brasileiro" (VELlOSO, 1987: 40). Dessa forma, percebe-se que durante a Era Vargas, especialmente no período da Ditadura do Estado Novo, pode-se acompanhar uma série de iniciativas governamentais, no campo das políticas culturais, tendo em vista localizar e legitimar não só os arranjos institucionais do regime, como igualmente a figura de seu chefe, Getúlio Vargas. Uma destas iniciativas destinou-se a uma revalorização do passado brasileiro, retomando a investigação, tão cara aos anos 1920, das características e sentido de nossa formação nacional.

Nesse sentido, inúmeros textos, dos mais diversos intelectuais (em livros, revistas e jornais), e inúmeros empreendimentos públicos (fundação de museus, criação do Serviço do Patrimônio Histórico e de núcleos do Instituto Histórico e Geográfico nos 
estados, etc.) contribuíram para a realização de uma releitura da História do Brasil. Uma das pedras de toque desta proposta estado-novista de História do Brasil voltava-se para o que se pode considerar uma "história do trabalho" ou uma "história da questão social" no Brasil. Nela, uma clara periodização é realizada, caracterizando-se então dois tempos básicos, a partir de uma intervenção política capital, expressa nas leis sociais doadas por Vargas. Esta iniciativa e esta figura se transformam, por exemplo, no referencial por excelência de um novo tempo, obscurecendo todos os seus antecedentes.

Esse empreendimento distingue-se de quaisquer outros que lhe são anteriores, tanto pelo imenso envolvimento direto do Estado, quanto porque os agentes especializados, nele envolvidos, podiam contar com recursos financeiros e tecnológicos de alcance e eficácia muito maiores. Entretanto, como destacou Ângela de Castro Gomes, é preciso não confundir o engajamento consciente de parcelas da burocracia estatal neste empreendimento com um simplista e maquiavélico exercício de "manipulação de massas". Os elementos simbólicos alocados e os sentimentos mobilizados por uma política cultural estatal não são escolhas arbitrárias, estando vinculados a tradições cujas raízes se encontram no passado de comunidades com identidades que têm que ser levadas em conta.

Se há um processo de seleção e recriação de símbolos, ritos e ideias, a legitimidade buscada fundamenta-se em fatos e valores preexistentes, que devem ser observados e respeitados, para então serem tratados pela propaganda oficial. É neste difícil equilíbrio que a diversidade social pode se transformar em homogeneidade política, que inclui áreas significativas de unidade cultural. Neste último espaço, avulta a definição e a divulgação de uma história nacional, capaz de identificar uma "origem" comum e, a partir dela, refletir sobre o presente e o futuro do Estado-nação.

No caso da revista, os objetivos eram atingir um grande público letrado, informando-o e esclarecendo-o sobre as transformações que se vinham processando na política, na economia, nas letras, nas artes, nas ciências etc., sob o governo Vargas. Em outras palavras, tinha a preocupação explícita de "formar consciências em apoio aos ideais do Estado Novo, que eram os ideais do presidente Vargas e da nacionalidade brasileira". 


\section{Cultura Política e seu projeto político-ideológico estadonovista}

No Estado Novo, a questão da cultura passou a ser concebida em termos políticos. O regime criou seus próprios aparatos culturais, que difundiam a ideologia oficial para o conjunto da sociedade. Entre as revistas destinadas a fazer a propaganda do regime incluíam-se Cultura Política, Ciência Política, Estudos e Conferências, Dos Jornais e outras de caráter mais efêmero como Brasil Novo e Planalto. Dirigida por Almir de Andrade $^{2}$, Cultura Política era a revista oficial, diretamente vinculada ao DIP. Por ocasião do quarto aniversário do Estado Novo, o próprio presidente Vargas enfatizou a importância de seu caráter doutrinário na construção das diretrizes do Estado Nacional.

Cultura Política circulou de março de 1941 até outubro de 1945. Era uma publicação bem divulgada, vendida nas bancas de jornais do Rio de Janeiro e de São Paulo. Seus colaboradores eram bem remunerados, recebendo normalmente o dobro do que pagavam as demais publicações. ${ }^{3}$ Conforme explicitava seu próprio subtítulo, Cultura Política era uma "revista de estudos brasileiros", destinada a definir e esclarecer as transformações socioeconômicas que passava o país. Além de relatar minuciosamente as realizações governamentais, a revista funcionava como uma espécie de central de informações bibliográficas, noticiando e resenhando todas as publicações sobre Vargas e o Estado Novo.

Segundo Cultura Política, os intelectuais tinham um papel de fundamental importância na estruturação da "nova ordem". Formadores da opinião pública, a eles cabia a função de unir governo e povo, traduzindo a voz da sociedade. A revista contava com a colaboração da nata da intelectualidade brasileira, abrigando as mais diversas correntes de pensamento. Entre seus colaboradores estavam os próprios ideólogos do regime: além de Almir de Andrade, Francisco Campos, Azevedo Amaral, Lourival Fontes e Cassiano Ricardo, e outros intelectuais como Graciliano Ramos, Gilberto Freyre e Nelson Werneck Sodré.

Sua estrutura chama atenção. Cada sessão era precedida de uma nota introdutória onde se explicitavam seus objetivos e princípios norteadores, seguindo-se notas bibliográficas sobre os autores. Essas características da publicação mostram a eficácia do projeto ideológico estadonovista, evidenciando sua modernidade.

\footnotetext{
${ }^{2}$ Foi subchefe do gabinete civil da presidência da República no governo Getúlio Vargas (1951-1954). Fundou e dirigiu, durante cinco anos (1941-1945) a revista Cultura Política, com 53 volumes publicados. ${ }^{3} \mathrm{O}$ que pode justificar, por exemplo, a colaboração de intelectuais opositores ao regime, como foi o caso de Graciliano Ramos.
} 
Como apontou Marcelo Barbosa Câmara, em sua tese de doutorado, Cultura Política-Revista Mensal de Estudos Brasileiros (1941 a 1945): um voo panorâmico sobre o ideário político do Estado Novo, a revista deve ser encarada de um prisma que não a circunscreva somente a instrumento do DIP concebido para a propaganda de cunho panfletário (CÂMARA, 2010: 51). Em seus 53 volumes, a publicação dirigida por Almir de Andrade ${ }^{4}$ buscou reunir intelectuais com o intuito de refletir sobre o que entendiam como cultura brasileira, a política e suas inter-relações.

Almir de Andrade na apresentação do primeiro número de Cultura Política discorreu sobre alguns elementos que podem ser considerados como reflexão e roteiro do que iria ser a nova publicação. Andrade acreditava em uma democracia que-segundo ele- viria de um Estado que protegeria o trabalho promovendo a ordem política e “..se destinaria a assegurar a paz, a concórdia, o bem estar, a felicidade dos que trabalham pelo bem comum" (Cultura Política; 1941: 6.). Em outras palavras, o Estado para Andrade é o oposto ao estado liberal, vai de encontro à concepção individualista e não irá servir “... meramente a fins políticos, mas essencialmente à cultura, à alegria, ao bem estar, à felicidade de todos e de cada um em particular" (Cultura Política; 1941: 6).

Almir de Andrade relata o convite para dirigir a Cultura Política feito por Lourival Fontes, diretor do DIP, e o que o governo pretendia com a revista: "Eu era amigo do Lourival Fontes, e ele quis fazer uma revista de cultura dentro do governo do presidente Getúlio Vargas. Tinha antes convidado várias pessoas, inclusive elementos do próprio DIP para organizarem a revista ${ }^{5}$, mas não sei por que eles não chegaram a organizá-la... Planejei a revista de uma forma que pudesse interessar ao público pela variedade de assuntos, pelo nível intelectual, e pudesse também reunir toda aquela intelectualidade que girava em volta do governo, alguns opositores do governo, mas que, para fazer uma revista de cultura, colaboraram" (ANDRADE, 1985).

É importante lembrar que o convite efetuado pelo então diretor do DIP a Almir de Andrade foi o resultado da publicação do livro Força, Cultura e Liberdade, em 1940 a pedido do próprio órgão. Já naquela obra - fruto do incentivo de Lourival Fontes Andrade traça as linhas mestras daquilo que seria a linha editorial da revista Cultura

\footnotetext{
${ }^{4}$ Almir de Andrade foi um dos principais ideólogos do regime estado-novista colocando como destaque neste papel seu trabalho como diretor de Cultura Política. Além dele, poderíamos destacar Francisco Campos como o arquiteto jurídico do regime, Oliveira Viana como o inspirador teórico e Azevedo Amaral o seu ideólogo.

${ }^{5}$ É importante ressaltar que outras intelectuais que tiveram a influência na formação dos que escreveram na revista não participaram da mesma. Neste caso enquadram-se, por exemplo, Alberto Torres já falecido na época ou ainda Francisco Campos e Oliveira Vianna.
} 
Política. Em carta a Vargas, datada de 27 de agosto de 1940, Andrade irá encaminhar o livro ao então Presidente da República expressando não só a admiração ao condutor do Estado Novo, mas esboçando algumas das diretrizes de sua reflexão política:

Num outro fato meditei longamente: se devia apresentar as ideias políticas de V.Exa. como expressões de uma ideologia particular e de uma doutrina pessoal ou se, ao contrário, devia integrá-las na corrente de tradições políticas e das mais profundas aspirações populares em que elas se inspiraram e de cujo ambiente retiraram esses traços tão originalmente brasileiros que as caracterizam. O próprio espírito que transpira nas afirmações constantes de V.Exa. fez com que me decidisse sem hesitar pela segunda alternativa. ${ }^{6}$

Assim, em Força, Cultura e Liberdade - Origens históricas e tendências atuais da evolução política do Brasil, Andrade trabalhará com duas argumentações que caminham de maneira complementar: o estudo da formação da cultura política do país feita por meio de fontes como Gilberto Freire, Sérgio Buarque de Holanda, Euclides da Cunha, Oliveira Viana ou Alberto Torres no sentido de demonstrar as características desta cultura política cotejando-a com o que Andrade considera serem os erros dos dirigentes políticos brasileiros da República brasileira de antes de 1930 na condução do Estado (CÂMARA, 2010:110-111).

Ao lado do estudo da cultura política brasileira o autor irá analisar - sobretudo através dos textos de A Nova Política do Brasil, periódico publicado pela José Olímpio Editora e que visava, através da publicação de discursos e textos de Vargas, divulgar suas ideias - as congruências entre a nossa cultura política e a sensibilidade do Presidente para percebê-la e por em prática políticas que fossem compatíveis com o Brasil.

No livro que seria a gênese da revista Cultura Política, Andrade demonstra a forma pela qual iria atuar como intelectual: a preocupação com o entendimento dos fenômenos da política brasileira, engajada em um projeto político específico que era a da Revolução de 30, seu corolário o Estado Novo, mas, principalmente, com o político Getúlio Vargas.

${ }^{6}$ Trecho da carta de Almir de Andrade a Getúlio Vargas. Fonte: site FGV-CPDOC. Classificação: GV c 1940.08.27. 
Dessa forma, com a colaboração destes intelectuais e sob a influência de outros, buscando colocar em suas páginas o que define como a cultura do Brasil, sobretudo no se que refere à cultura política, ou seja, a formação do que seria a ideal organização do ponto de vista da formação cultural, Cultura Política vai às bancas.

A distribuição da revista era feita nas bancas de jornais de todo o país e organizada por Fernando Chinaglia. Cultura Política, com uma tiragem de três mil exemplares, era uma revista que não possuía um conteúdo para consumo popular, como observa Andrade, "era outro tipo de revista, pesada, maçuda", mas com a distribuição organizada de tal forma que seu primeiro número, segundo Andrade, "um grande sucesso de vendagem". Apesar de não ser produzida para as massas, não teve sua distribuição dirigida somente a uns poucos escolhidos pelo regime ou distribuída como panfleto de apologia ao regime.

A maioria dos autores da revista era oriunda ou gravitava em torno da burocracia do Estado. Mais de $80 \%$ dos autores dos artigos sobre "política" estão de algum modo, vinculados à burocracia estatal e colaboraram com quase $85 \%$ do total das matérias. Portanto, a maior parte da ideologia política do regime difundida em Cultura Política é formulada pela burocracia do Estado", como pode-se observar na tabela abaixo (CÂMARA, 2010: 55).

\section{Tabela 1}

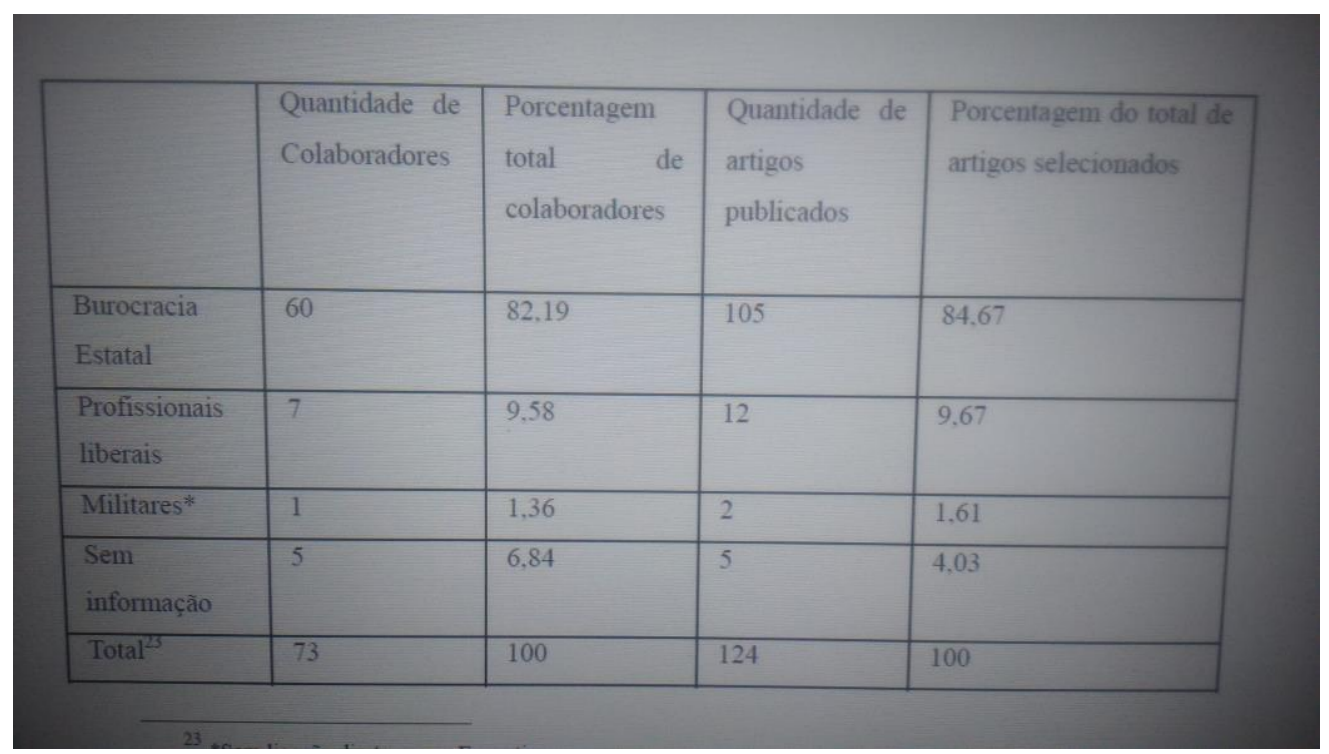

Fonte: CÂMARA, 2010:56. 
Observa-se, portanto, que o espírito nacional de um país podia, seguindo a revista Cultura Política, muito bem ser encontrado/produzido nos costumes, na religião, na língua e no passado do povo. Toda a política do pós-37 era uma reação às orientações anteriores que romantizavam o futuro, hipervalorizavam o presente $\mathrm{e}$ condenavam e temiam o passado. Havia um erro "original” de nossas elites políticas no tratamento dos "tempos", que estava sendo corrigido pelo Estado Novo. Ele enfrentava os problemas do presente, sem idealizações do futuro, exatamente porque não se negava a refletir sobre o passado, entendendo-o como um manancial de inspiração. O passado, segundo tal orientação, não poderia mais ser tratado como uma espécie de fantasma a assombrar e poluir o espírito nacional, não só por seu desconhecimento, como também por um certo sentimento de inferioridade que precisava ser definitivamente exorcizado.

Como um manancial de inspiração ele devia funcionar como uma bússola a orientar a nova política nacional, que desacreditava de modelos universais, investindo em diretrizes eficazes porque sintonizadas com a realidade singular de cada nacionalidade. Como se pode verificar, impunha-se, para as finalidades de realismo político do governo Vargas, uma nítida valorização do passado, o que implicava tanto uma leitura positiva, mas não idealizada, sobre ele, como a implementação de iniciativas que o divulgassem junto a população em geral. O "lugar" do passado na política cultural estado-novista é assim crucial, mas ele não é delineado de forma "unitária", havendo duas concepções sendo propostas e convivendo lado a lado.

Primeiramente, a de um passado ligado à cultura popular e que, manifestando-se através de um conjunto de tradições - festas, lendas, mitos, canções, costumes alimentares, práticas religiosas e medicinais etc. -, convivia com o presente, encerrando uma ideia de tempo não-datado. Este passado apontava de maneira forte um sentido de continuidade na formação nacional brasileira, não excluindo diversidades próprias à sua concepção mais "espacial", particularmente compreensível pelo tamanho de nosso território.

Ao lado deste passado "tradicional" e "espacial" da cultura popular, havia outro passado, "histórico", ligado a uma ideia de tempo linear, datado e referido à memória de fatos e personagens únicos, existentes numa sucessão, à qual é, vedado conviver com o presente. Ambos os sentidos de passado, ambas as formas de postular sua relação com o presente e o futuro, contudo, convergiam para a meta de recuperação e valorização da memória do povo brasileiro. Nela, o "lugar da história" seria extremamente relevante porque aí se situava o inspirador e diretor máximo de todo este esforço: o presidente 
Vargas. Esta releitura da história do Brasil então empreendida teve alguns eixos capitais que podem ser apreendidos pelo conjunto de artigos de Cultura Política. ${ }^{7}$

O primeiro a ser apontado, diz respeito à construção de uma interpretação de nossa ' história que postula ter ela um verdadeiro "sentido", identificado no processo de centralização política iniciado com Tomé de Souza, no período colonial, e ganhando contornos definitivos com Getúlio Vargas.

O segundo eixo interpretativo é bem menos evidente e envolve uma leitura dos acontecimentos históricos onde se procura demarcar que, na luta contínua por autonomia/independência/soberania, o povo brasileiro, esposava valores e ideais cuja realização se concretizou apenas sob o regime republicano. Isto é, sem descurar da "glória imperial", centralizadora e responsável pela unidade religiosa e territorial, a história do Brasil então proposta era a de um "povo republicano", sendo a ideia de República associada a da verdadeira liberdade e democracia ante modelos internacionais, mais uma vez expressas pelo Estado Novo. Inúmeros artigos da seção História retomam os episódios das lutas travadas no período colonial e imperial para acentuar os sentimentos republicanos que os permeavam, destacando-se personalidades como Tiradentes e várias lideranças pernambucanas dos séculos XVIII e XIX.

Esta interpretação se reforçava com um terceiro ponto, que remetia fundamentalmente à questão de uma periodização para a história do Brasil. Neste caso, diversos articulistas revisitam alguns dos mais emblemáticos acontecimentos de nossa história, como a Independência, a Abolição e a própria proclamação da República, com a finalidade de destacar que eles não tiveram "grande beleza", ou porque foram mais episódios simbólicos - datas fechando um processo em curso, casos da Independência e da República -, ou porque foram atos cujos desdobramentos causaram grandes problemas à nação, caso exponencial da Abolição.

Desta forma, na ótica de Cultura Política, como grande divisor do tempo histórico emergia a Revolução de 1930 e seu corolário, o Estado Novo, que finalmente garantira a soberania do país sob um regime republicano e centralizador. Como maior evento deste novo tempo, apontava-se o enfrentamento definitivo da "questão do trabalho", finalmente solucionada pela grande obra legislativa de chefe/amigo/pai Getúlio Vargas.

\footnotetext{
${ }^{7}$ Um trabalho com esta seção da revista, de forma mais alongada, foi empreendido no livro de Ângela de Castro Gomes, História e historiadores: a politica cultural do Estado Novo (Gomes, 1996).
} 
Durante os anos que foi publicada, sob a direção de Almir de Andrade, Cultura Política refletiu o regime de Getúlio Vargas no sentido de divulgar questões ligadas a estruturação política do Estado Novo e em especial procurando manter-se como uma revista- segundo a definição de seu editor- de cultura e política, de maneira a refletir algo de caro ao Estado Novo: a construção de uma Nação calcada em sua própria cultura e um regime político que por ela se estruturasse.

Assim, temáticas como antiliberalismo, integração nacional, política externa brasileira, sindicalismo, política imigratória, Estado Novo, a Constituição de 1937, federalismo, Segunda Guerra Mundial, governo e a economia do país, artes, Amazônia, previdência social, educação física, produção de petróleo, siderurgia e administração pública são algumas das questões levantadas pela publicação, editada de março de 1941 a outubro de 1945.

No Brasil daquele momento do século XX e sob a égide dos partidários do Estado Novo podemos desdobrar a crítica ao liberalismo em dois aspectos: primeiro, o reflexo da crise pela qual passava o liberalismo naquele período pelo mundo, e em segundo lugar, mesmo que a democracia da Primeira República tivesse concretamente pouco de democracia e pouco de liberalismo, era em boa medida, a partir de elementos do discurso liberal, que parte da imagem daquele simulacro de democracia foi construída, ao menos para os que tinham acesso àquela esfera pública exígua.

Acerca desta questão Elide Rugai Bastos observa que "na revista Cultura Política a crítica ao liberalismo tem um endereço certo: mostrar os erros cometidos na Primeira República e justificar as experiências centralistas do presente, anos 1930, apontando para o acerto das decisões centralizadores do passado, indicando essa tradição política como a mais adequada ao perfil nacional. Esse objetivo leva a que vários artigos sejam dedicados à reconstituição da história brasileira, tanto para lembrar o bom êxito da centralização política como para apontar os equívocos resultantes da persistência dos valores oligárquicos”. (BASTOS, 2006: 131.)

Especificamente, quanto a linha editorial da revista, ela foi pautada, em boa parte e no que interessa a este artigo, na análise de temas que gravitaram em torno de questões como: Porque o liberalismo era considerado algo inadequado ao homem e a sociedade brasileira? ( $\mathrm{n}^{\mathrm{o}} 5$; 1941); Qual o papel dos sindicatos? ( $\left.\mathrm{n}^{\circ} 10 ; 1941\right)$; Quais eram as perspectivas para o Estado Nacional na concepção estadonovista? (nº 11; 1942); Qual a boa inserção do Estado na economia? (nº 5; 1941); A administração pública no 
Estado Nacional no período Vargas ( $\left.\mathrm{n}^{\circ} 20 ; 1942\right)$; Como se daria a centralização da administração no estado nacional? ( $\left.\mathrm{n}^{\circ} 11 ; 1942\right)$.

Cultura Política possuía, em seu lançamento, uma estrutura assim delineada em seis seções: Problemas Políticos e Sociais, O Pensamento Político do Chefe de Estado, A Estrutura jurídico-política do Brasil, Textos e Documentos Históricos, A Atividade governamental e Brasil social, intelectual e artístico. Essa configuração, com algumas alterações a partir da nomeação do major Coelho dos Reis para a direção do DIP, em agosto de 1942, perdurou até maio de 1945, quando a revista deixou de ser vinculada ao DIP- extinto naquele mesmo mês pelo Decreto-Lei n 7582 que criaria o Departamento Nacional de Informações-DNI (CÂMARA, 2010: 65).

De agosto a outubro de 1945, Almir de Andrade- por iniciativa empresarial própria- publicou os números de 51 a 53, suas últimas edições. Mesmo com o fim de sua publicação, Cultura Política surge, hoje, como fonte histórica de um período autoritário da história brasileira. Como se viu, a revista integrava um vasto e diversificado conjunto de iniciativas governamentais destinado a fazer a propaganda do novo regime através da mobilização de recursos culturais.

Para isso, reserva, em suas páginas, um "lugar" bem amplo para a história e, sobretudo, a compreende através de uma multiplicidade de formas. Todas, contudo, como observa Ângela de Castro Gomes, tem um ponto de convergência básico: histórica, na revista, é a história do povo brasileiro, o que inclui grandes homens- os heróis-, e também os homens comuns, os anônimos, mas exclui a história de outros povos, que só nos diz respeito quando muito diretamente ligada a episódios específicos e significativos de nossa própria história (GOMES, 1996:158-159). Observa-se, portanto, que a recuperação do passado histórico era, sem dúvida, uma tarefa imperiosa, pois só assim tornava-se possível compreender uma série de dificuldades, aprendendo nossa força e potencialidade, para construir um novo país: uma nova história.

\section{Conclusão}

Observa-se, portanto, que durante o período estado-novista (1937-1945) houve uma tentativa de centralizar a produção de literatura histórica brasileira para o desenvolvimento de uma ampla, sistemática, diversificada e sofisticada política cultural no Brasil. Como observou Marcelo Barbosa Câmara, é possível demonstrar quais as ideias que deram alma as políticas do Estado Novo a partir do conteúdo dos artigos dos 
intelectuais que colaboraram em Cultura Política, ressaltando que a revista não se circunscreveu a um mero instrumento de propaganda do regime. Se também teve este papel, o conjunto de seus artigos aponta para além da preocupação do embate político imediato e da estrita defesa conjuntural do regime de Vargas, fato que não deve ser descartado, mas não se constitui como a totalidade da essência da revista.

Por fim, a reflexão acerca do tema cultura política efetuada pelo pensamento político autoritário e em especial a contida na revista Cultura Política centrou-se fundamentalmente na crítica à democracia da República Velha, crítica que fundamentou suas propostas para a construção de uma nova sociedade que seria gerida pelo regime instaurado em 1937, o Estado Novo. A revista tinha, portanto, como objetivo ser "um espelho do Brasil em tempo de renovação”. (ANDRADE,1941: 8)

\section{Fontes}

Cultura Política; março de 1941; ano I no. 1; p. 6. Disponível em: $<$ http://memoria.bn.br/DOCREADER/DOCREADER.ASPX?BIB=163538>. Acesso em: 14 jan. 2016.

\section{Referências Bibliográficas}

ANDRADE, Almir de (1941). A evolução política e social do Brasil. Cultura Política (1); mar, p. 8.

ANDRADE, Almir de. (1985) (Depoimento, 1981). Rio de Janeiro: FGV/CPDOCHistória Oral.

BASTOS, Elide; RIDENTI, Marcelo; ROLLAND, Denis (2006). Intelectuais e Estado. Belo Horizonte: Ed. UFMG.

CÂMARA, Marcelo Barbosa (2010). Cultura Política- Revista Mensal de Estudos Brasileiros (1941 a 1945): um voo panorâmico sobre o ideário político do Estado Novo. São Paulo: PUC/SP. Tese de doutorado.

GOMES, Ângela de Castro (1996). História e historiadores. Rio de Janeiro: Editora Fundação Getúlio Vargas.

VELLOSO, Mônica Pimenta (1987). Os Intelectuais e a política cultural do Estado Novo. Rio de Janeiro: Fundação Getúlio Vargas/CPDOC; 1987. 
Artigo recebido em 14 de março de 2017.

Aprovado em 11 de maio de 2017.

DOI: 10.12957/intellectus.2017.27378 